\title{
The Application of the Normal Lymphocyte Transfer Reaction to Histocompatibility Testing in Man*
}

\author{
C. B. Carpenter, $†$ R. J. Glassock, R. Gleason, J. M. Corson, and J. P. Merrill \\ (From the Departments of Medicine and Pathology, Harvard Medical School, and the \\ Cardiorenal Laboratory and Division of Mathematical Biology, Peter Bent \\ Brigham Hospital, Boston, Mass.)
}

Recent advances in human kidney transplantation have brought the need for a more careful analysis and understanding of histocompatibility in man. The results of human renal allografting indicate that although parents or siblings are the best donors, grafts from unrelated donors occasionally survive for prolonged periods (1), presumably due to chance compatibility. A means for measuring histocompatibility in man is, therefore, needed. To this end, a number of experimental approaches have been proposed, namely leukoagglutination (2-4) and lymphocytotoxic serotyping $(5,6)$ of tissue antigens; interaction of allogeneic lymphocytes in vitro (7-9) ; cross reactions in skin transplantation, the so-called third man test (10) ; skin reactions produced by lymphocytes in irradiated hamsters (11); and the normal lymphocyte transfer reaction (NLT).

This latter phenomenon, described by Brent and Medawar (12) in the guinea pig, is a result of the transfer of viable peripheral blood lymphocytes from one individual to an intradermal site in another individual. The immunologically competent cells are presumably able to react in a graft vs. host fashion against the histocompatibility antigens in the dermis of the cell recipient, forming a reaction that is expressed as an inflammatory nodule in the skin, reaching its peak approximately 48 hours after inoculation. In the guinea pig the intensity of the reaction was shown to cor-

\footnotetext{
* Submitted for publication January 17, 1966; accepted June 8, 1966.

Supported in part by U. S. Public Health Service grants 5R01 HE 08260-01+2, AI-06091, 5-TI-GM-98402+03, GM-10002-02+03, HE-01771, and 8M01-FR-31. Also supported in part by a John A. Hartford Foundation grant and U. S. Army Research and Development contract DA 49-193-MD-2061.

† Address requests for reprints to Dr. Charles B. Carpenter, Peter Bent Brigham Hospital, 721 Huntington Avenue, Boston, Mass. 02115.
}

relate with the duration of skin graft survival when skin was grafted back to the lymphocyte donor. Subsequently, by use of inbred and hybrid strains, the graft vs. host nature of the reaction was formally demonstrated (13).

As foreseen by Brent and Medawar, the extension of these studies to man has led to certain problems, some of which have been discussed by subsequent investigators (14-17). These include differences in $\mathrm{ABO}$ antigens and sex, preimmunization of cell donor or recipient, or both, differences in the skin reactivity of lymphocyte recipients, and the possibility of transferring viral disease to the cell recipient.

It is the purpose of this paper to present the results of an investigation of the NLT phenomenon in man, including gross and microscopic observations of the reaction, studies in monozygotic and dizygotic twins, studies on the influence of uremia, observations on the predictive value of the test as applied to skin grafting in normal volunteers, and the results of prospective and retrospective studies in recipients of kidney transplants. Other investigators have stressed the need for careful clinical studies of the NLT reaction $(12,15)$, there being an important need to determine its value in "matching" humans for allografting. Even though there have been several studies on the NLT reaction in man, few have provided information on its relationship to allograft survival. Although this analysis will point out some of the deficiencies of the test as currently applied to man, it nevertheless provides evidence that the NLT reaction has some predictive value when related donors are considered for renal transplantation.

\section{Methods}

Selection of subjects. Individuals studied in these experiments were either normal healthy volunteers or donor-recipient pairs in an experimental renal transplantation program. The history and routine clinical 
evaluation were relied upon to rule out hepatitis or other transmissible diseases, allergies, or connective tissue diseases. Subjects taking antihistaminic, anti-inflammatory, or immunosuppressive drugs, with the exception of patients after transplantation, were excluded from the study. Histories of blood transfusion and pregnancies were noted and the major red cell groups recorded.

Skin grafting. The method of Wilson, Henry, and Merrill (10) was employed with the following modifications: All full thickness grafts were elliptical in shape, $2 \times 4 \mathrm{~cm}$, and held in place with light compression by a stint of fine mesh gauze. With few exceptions, the donor skin was removed under local anesthesia from the inner aspect of the upper arm and grafted to prepared sites in the same area on the recipient.

Normal lymphocyte transfer. The reaction to intradermal injections of concentrated suspensions of lymphocytes obtained from peripheral blood was evaluated in prospective donor-recipient pairs before renal allotransplantation, in donor-recipient pairs after successful transplantation, and in monozygotic and dizygotic twins. In addition, panels of healthy volunteers were used to compare the NLT results with skin graft rejection patterns.

Method for preparation of lymphocytes from peripheral blood. The general method of Brent and Medawar (12) was used with a few modifications and has been described in detail previously (18). Venous blood was collected under-sterile conditions and immediately transferred to $20-\mathrm{ml}$ screw cap glass jars containing eight glass beads (diameter $4 \mathrm{~mm}$ ) and agitated for approximately 15 minutes to ensure complete defibrination. It was then aspirated through a glass wool filter into a syringe containing dextran (average molecular weight $188,000)$ in $0.9 \%$ saline solution, such that the final concentration of dextran was 1.5 to $3.0 \%$. The dextransaline-blood mixture was then allowed to sediment for approximately 30 minutes at $37^{\circ} \mathrm{C}$. The supernatant fluid was withdrawn and centrifuged for 10 minutes at room temperature in a PR-2 International centrifuge at $1,500 \mathrm{rpm}(800 \times g)$. Some of this supernatant fluid was saved for control injections, whereas the packed cells were resuspended in a volume of supernatant approximately three times the volume of the packed cells. This suspension was resedimented at $37^{\circ} \mathrm{C}$ for an additional 30 to 45 minutes to allow for more complete removal of red cells. The lymphocyte-rich supernatant was carefully aspirated directly into disposable plastic $1.0-\mathrm{ml}$ tuberculin syringes. A portion of the cell suspension was dropped onto a glass slide and used for cell counts, viability testing, and differential counts, and the remainder was used for intradermal injections. Bacteriologic cultures were obtained of all suspensions. Cell counts were made by conventional dilution in leukocyte pipettes and were counted in a hemocytometer chamber under phase contrast microscopy. Smears were stained by Wright's method. Viability was tested by the method of Pappenheimer (19) using 1:2,000 trypan blue in Tyrode's solution. Final yields were calculated and expressed as total cells per $0.1 \mathrm{ml}$, total lymphocytes per $0.1 \mathrm{ml}$, and granulocyte percentage.
Cell suspensions were injected intradermally on the volar surface of the forearm in $0.1-\mathrm{ml}$ amounts through a 26-gauge disposable needle, taking great care to avoid direct intralymphatic injection. Since considerable variation was noted in the ease with which the superficial lymphatics could be inadvertently injected, one of the control injections of the serum-dextran-saline mixture was usually given first as a test of the peculiarities of the individual's skin. In some instances, cells were rendered nonviable by multiple freeze-thaw cycles in dry ice and acetone $\left(-70^{\circ} \mathrm{C}\right)$ or by heating at 50 to $60^{\circ}$ for 1 hour. In most instances cell donors were injected with their own cells as autologous controls.

Measurement of skin test reactions. The skin test sites were inspected at 24 and 48 hours and periodically thereafter as circumstances allowed. The results were recorded independently by three, and occasionally two, observers. The extent of the skin reaction was quantitated by measuring erythema and induration separately in millimeters of greatest diameter. Recording results in this fashion permitted evaluation of erythema and induration separately and allowed statistical analysis of the results. Biopsies of selected skin reactions were taken at various times.

Arrangement of panels of volunteers for skin testing and grafting. In studying healthy unrelated volunteers, we elected to follow the model of Brent and Medawar (12) in which skin was simultaneously transplanted from several lymphocyte recipients back to the lymphocyte donor. Such a system served as a model for the clinical situation in which several potential kidney donors would be tested vs. the proposed recipient. We hoped it would also help to establish whether erythema or induration at 24 or 48 hours was the best measure of the putative graft vs. host reaction. No attempt was made to control the sex or blood group compatibilities of the five individuals in each of the three panels. Full thickness skin grafts from the four lymphocyte recipients to the cell donor were accomplished on the same day as the lymphocyte transfers. The four grafts were placed in proximity to each other, along with an autograft, on the inner surface of an upper arm, as described above. The grafts were inspected daily by two or more observers beginning on the sixth day, and the onset of rejection of each graft was determined grossly by the appearance of edema in the graft. Erythema was not used as a major criterion in accordance with the findings of Marshall and associates $(20,21)$. Biopsies were taken of all grafts a day or two after the first appearance of gross evidence of rejection in any one of them. Ranking of the skin test reactions was facilitated by the use of Duncan's new multiple range test (22).

\section{Results}

The composition of lymphocyte suspensions. Treatment of peripheral blood by defibrination, dextran sedimentation, and centrifugation as described produced reasonably pure suspensions of lymphocytes, although the over-all yield was rarely 


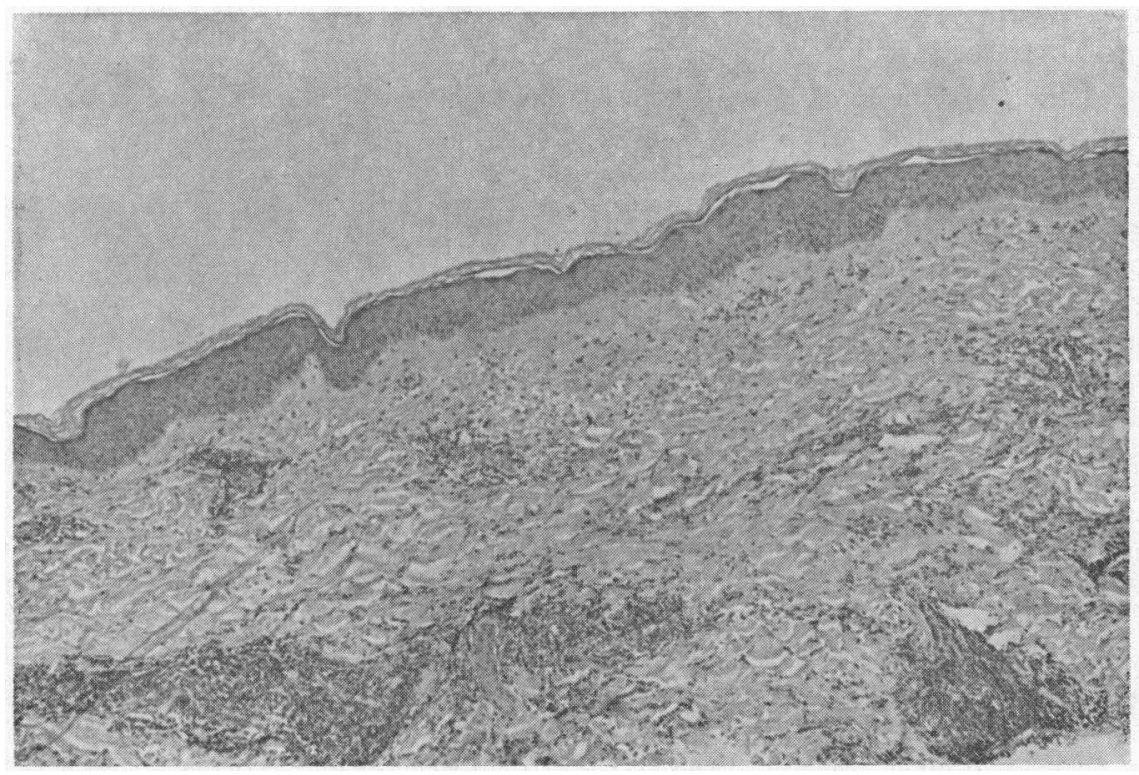

Fig. 1. Skin, 48 HOURS AFTER INJECTION OF PERIPHERAL BLOOD LYMPHOCYTES. There is extensive perivascular mononuclear cell infiltration.

more than $25 \%$ of the lymphocytes contained within the original blood sample. It generally required, therefore, $50 \mathrm{ml}$ of whole venous blood to prepare 0.3 to $0.6 \mathrm{ml}$ of cell suspension. In the series reported here, the mean concentration of lymphocytes was $3.5 \times 10^{6}$ per $0.1 \mathrm{ml}$ from normal subjects and $3.3 \times 10^{6}$ per $0.1 \mathrm{ml}$ from uremic subjects. The mean degree of contamination with polymorphonuclear leukocytes was $8.6 \%$ in normal and $15.4 \%$ in uremic subjects. There were always a few platelets and red blood cells present as well, but the ratio of leukocytes to erythrocytes was at least 2 or 3 to 1 . Although there was no significant difference in composition between the cell suspensions prepared from normal and uremic subjects, there was greater variation in the latter, and it was at times very difficult to obtain sufficient cells from a few of the uremic patients.

The nature of the NLT reaction. The erythema and induration produced by the intradermal injection of allogeneic lymphocytes grossly resembled a delayed cutaneous hypersensitivity reaction such as the response to tuberculin. There was a central raised area of induration, sometimes slightly painful, with a surrounding area of erythema that blanched on gentle pressure. Sometimes induration was soft and indistinct, whereas occasionally the area of erythema was very large, with indistinct margins and irregular outlines. The majority of the lesions produced in these studies were less than $10 \mathrm{~mm}$ in transverse diameter. In- duration of less than $2 \mathrm{~mm}$ unaccompanied by erythema was called a negative response, since such small areas could not always be distinguished from the effects of needle trauma. An important feature of the NLT reaction, shared by delayed hypersensitivity, is that maximal responses are observed between 24 and 48 hours after injection. In a majority of instances erythema was maximal at 24 hours, whereas induration present at 24 hours remained relatively stable at 48 hours, although in some cases it was larger on the second reading. In 20 transfers among healthy unrelated individuals there were no negative reactions, and in 39 transfers from uremic to healthy individuals, there were only two negative reactions. In no case was there evidence for any reaction other than the local skin lesion; there were no systemic symptoms or regional lymph node enlargements.

The size of the NLT reaction was found to be dose related only at rather extreme cell counts in our limited studies of dose-response relationships in which various dilutions of lymphocytes were injected into two normal recipients, using cells from two donors, one of whom was uremic. In each case, cell doses from $1.0 \times 10^{6}$ to $4.0 \times 10^{6}$ produced equal reactions in the same recipient. Although not as well documented, the impression was gained that doses of over 5 to $6 \times 10^{8}$ lymphocytes did produce significantly larger reactions, and that cell doses as low as $0.5 \times 10^{6}$ could produce measurable reactions, results similar to those of Gray 


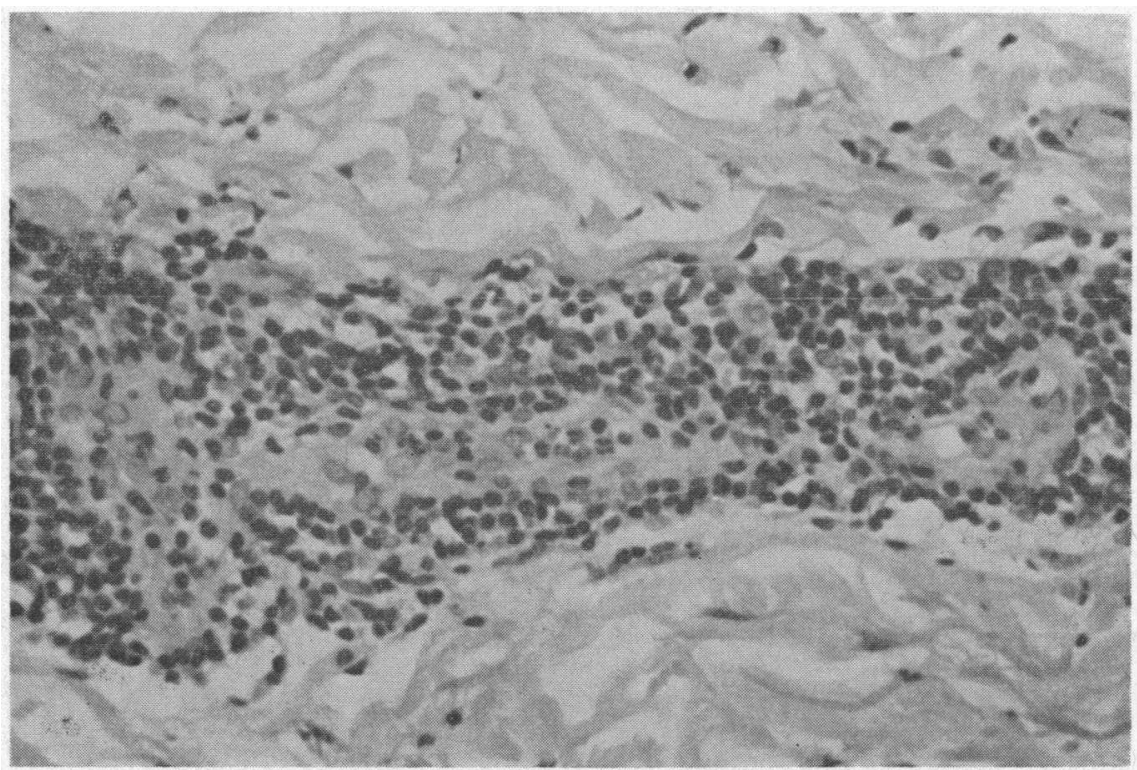

Fig. 2. Skin, Higher magnification of Figure 1. The infiltrate is of lymphocytes and histiocytes. In the vessel, cut in longitudinal section, endothelial cells are swollen, and the lumen contains neutrophils and mononuclear cells.

and Russell (17). Contamination with granulocytes did not alter the general spectrum of response, that is, suspensions containing larger numbers of granulocytes did not necessarily produce greater areas of erythema. The serum-dextransaline control injections were uniformly negative at 24 and 48 hours. In many instances, devitalized cells produced by heating or freezing and thawing were injected in parallel with viable cells from the same source. At times there was no reaction to the dead cells, but there often was some induration and erythema at 24 hours that generally subsided entirely by 48 hours. Four out of seven recipients of nonviable cells developed erythema of 10 to $24 \mathrm{~mm}$ with 3 to $7 \mathrm{~mm}$ of induration at 24 hours. It was apparent, therefore, that part of the 24-hour reaction was nonspecific in the sense that it could not have been based upon the competency of the injected cells. The 48-hour reaction was, therefore, considered to be the most reliable index of the putative graft vs. host reaction.

Upon microscopic examination 48 hours after injection of lymphocytes from peripheral blood into the dermis, perivascular areas were heavily infiltrated by mononuclear cells (Figure 1). The infiltrate was composed largely of lymphocytes and lesser numbers of histiocytes (Figure 2). In the central area of the dermis the mononuclear cells extended into the collagen, and at this site there were scanty neutrophilic infiltration and scattered nuclear debris. Mitotic figures were not seen. In vessels encompassed by the cellular infiltrate, there were congestion, leukostasis, and endothelial cell swelling (Figure 2). The appearances of biopsies at 24 hours after injection of peripheral blood lymphocytes and at 48 hours after injection of thoracic duct lymphocytes were qualitatively similar to the above.

A recurrence of erythema and induration (17, 23 ), not necessarily of the same magnitude as the first reaction, occurred in a majority of our cases, although we did not have the opportunity to observe all of our recipients at the proper time. In some instances, however, the recrudescent lesion in individuals who had positive reactions at 48 hours did not occur at any time. The most typical case demonstrated a biphasic reaction with subsidence of the initial reaction on the fourth or fifth day and the appearance of the second reaction on the sixth to the eighth day in the sites injected with viable cells. The second response consisted of a very firm raised indurated area with a relatively small area of erythema, although the central area was intensely dusky and erythematous. 


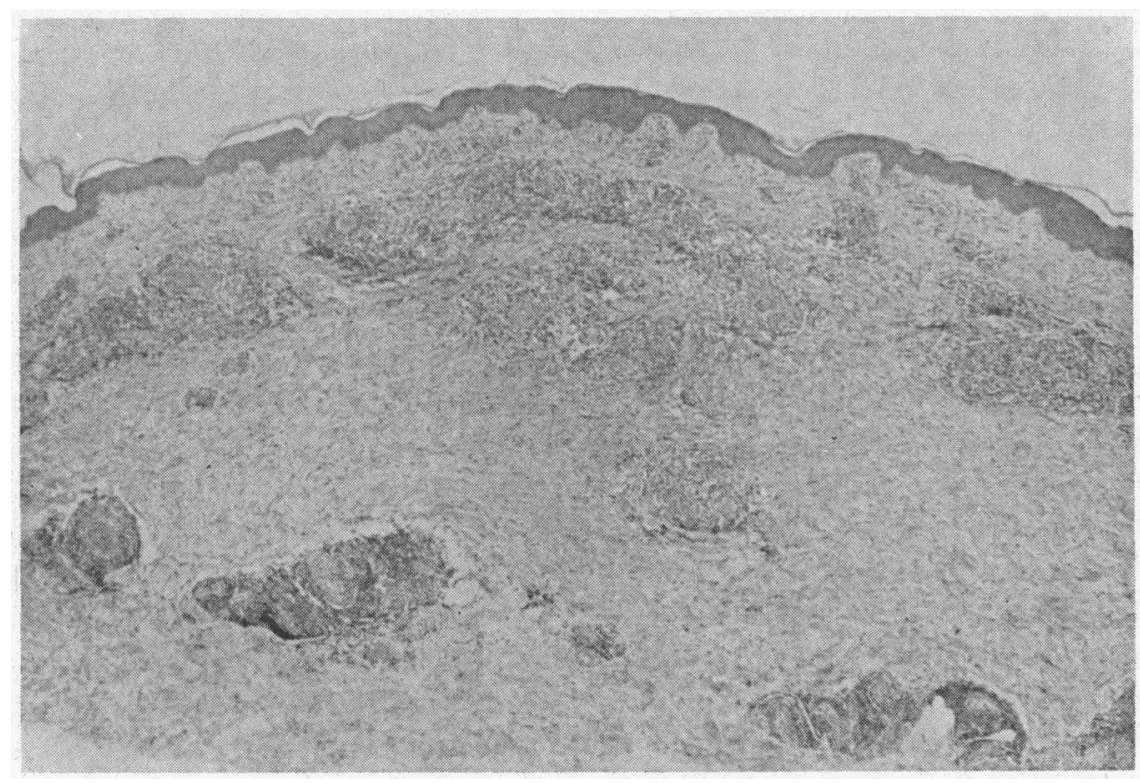

Fig. 3. SKIN, 8 days AFTER INJECTION OF PERIPHERAL BLOOD LYMPHOCYTES. In the dermis, there is an extensive mononuclear cell infiltrate, which is predominantly perivascular.

When examined microscopically, an 8-day recrudescent lesion displayed a prominent mononuclear cell infiltrate in the dermis (Figure 3 ). The infiltrate, composed of lymphocytes and histiocytes (Figure 4), was principally perivascular, but in foci it extended into dermal collagen. In vessels surrounded by cells there were congestion, leukostasis, and endothelial cell hypertrophy (Figure 4). The epidermis was unaltered. The 8-day biopsy differed from the 2-day biopsy in that histiocytes were much more numerous in the recrudescent lesion and polymorphonuclear cells and nuclear debris were absent.

After 3 or 4 days, the recrudescent lesion also faded. Skin sites injected with the serum-dextransaline or nonviable cell controls did not participate in the second response. A few individuals did not have a clearly biphasic pattern, but they had what appeared to be a persistence of the first reaction for over a week. Of special interest was the experiment in a dizygotic twin pair in which skin and lymphocytes from the uremic twin (A.J.) were transplanted to the healthy twin on the same day. The moderate NLT response (Table III) was followed by a late recrudescent lesion at the skin test site on the fifteenth day, at which time the skin graft showed the first signs of rejection, sug- gesting that both reactions were of a host vs. graft nature.

The histologic pattern of the early reaction was similar to that described by Gray and Russell (17), and in both early and late reactions the pattern was similar to that observed in the tuberculin reaction, in that the response was primarily mononuclear and perivascular. Although the changes in vessels were remarkable, alterations clearly indicative of an Arthus reaction were not present. It is important to stress that mitotic figures were not seen in our studies, a point in disagreement with the previously published data (17). In addition, eosinophils and basophils were very sparse in these histological sections, although the exudates obtained from NLT reactions by the skin window technique were said to be rich in these cells (24).

The NLT reaction to autologous and isologous cells. There were uniformly negative reactions to the injection of autologous cells at 48 hours; however, four of eight autologous injections showed erythema of 3 to $25 \mathrm{~mm}$ at 24 hours. Bacterial contamination was ruled out as a factor by cultural studies. In the five instances where cells were exchanged between monozygotic twin pairs, three of the five showed erythema of 2 to $7 \mathrm{~mm}$ at 


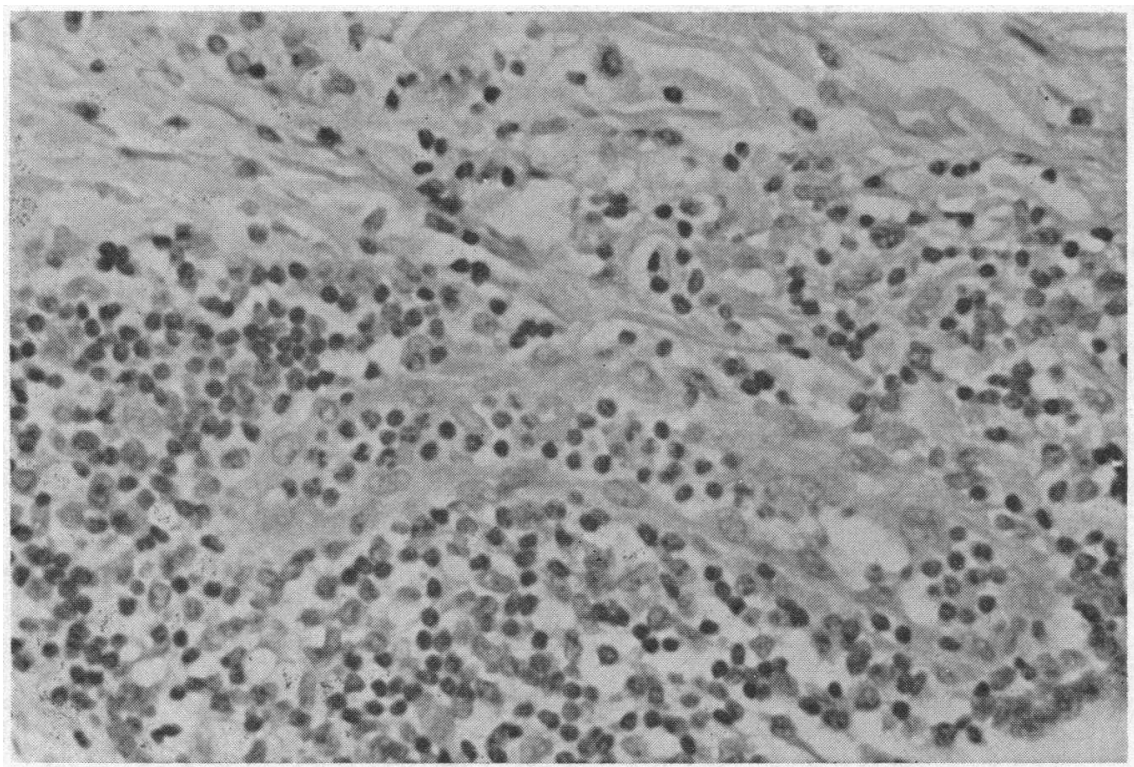

Fig. 4. Skin, higher magnification of Figure 3. The infiltrate is perivascular and mononuclear. Leukostasis and endothelial cell hypertrophy are seen in a vessel cut longitudinally.

24 hours, whereas all were negative at 48 hours. There was no relation between the percentage of granulocyte contamination and the occurrence of erythema, and no induration was produced by autologous or isologous cells. In contrast were the positive reactions obtained when cells from uremic dizygotic twins were injected into the healthy twin. These reactions were similar in magnitude to those obtained with unrelated individuals, and in the three dizygotic twin pairs studied the results were taken as additional evidence for nonidentity.

The effect of uremia on the NLT reaction. Although comparison of the reactions produced by the cells of uremic patients as a group with those produced by the cells of normal individuals strongly suggested that uremia per se was an important modifying factor, only a study of monozygotic twins enabled us to observe this effect uncomplicated by varying degrees of histoincompatibility. Equal numbers of lymphocytes from each member of two monozygotic twin pairs were tested against two pairs of healthy unrelated recipients. Both sets of twins had been proven to be isogeneic by skin grafting and blood grouping. As shown in Table $I$, the reactions produced by the uremic cells were less than those produced by the healthy cells in all recipients. Forty days after successful transplantation of a kidney from the healthy twin L.R. to the uremic twin F.R., the experiment was repeated using two different recipients. At this time, there were only slight differences between the two sets of lesions, indicating that competency had improved after the return of normal renal function. It should be noted, however, that the uremic cells did produce some reaction and that erythema was depressed relatively more than induration.

TABLE I

Effect of uremia in isogeneic lymphocyte donors on NLT reaction*

\begin{tabular}{|c|c|c|c|c|}
\hline \multirow[b]{3}{*}{ Lymphocyte donors } & \multicolumn{4}{|c|}{ Lymphocyte recipients } \\
\hline & \multicolumn{2}{|c|}{ Pretransplant } & \multicolumn{2}{|c|}{$\begin{array}{c}\text { Post-tránsplant } \\
\text { (40 days) }\end{array}$} \\
\hline & M.H.† & T.H.† & D.S.t & H.D.f \\
\hline $\begin{array}{c}\text { Identical F.R. (uremic) } \\
\text { twins L.R. (healthy) }\end{array}$ & $\begin{array}{l}22.0 / 4.5 \\
37.0 / 6.0\end{array}$ & $\begin{array}{r}8.0 / 5.0 \\
41.0 / 7.5\end{array}$ & $\begin{array}{l}6.0 / 5.0 \\
8.0 / 6.0\end{array}$ & $\begin{array}{l}6.0 / 6.0 \\
6.0 / 7.0\end{array}$ \\
\hline $\begin{array}{c}\text { Identical N.B. (uremic) } \\
\text { twins } \\
\text { A.B. (healthy) }\end{array}$ & $\begin{array}{c}\text { MeB\& } \\
6.5 / 4.0 \\
11.5 / 6.5\end{array}$ & $\begin{array}{c}\text { AnB } \\
13.5 / 4.0 \\
17.0 / 7.3\end{array}$ & & \\
\hline
\end{tabular}

* Erythema/induration at $\mathbf{4 8}$ hours in millimeters. NLT = normal lymphocyte transfer.

$+2.4 \times 10^{\circ}$ lymphocytes from each donor; $4 \%$ granulocyte contamination.

$\pm 2.3 \times 10^{6}$ lymphocytes from each donor; $16 \%$ granulocyte contamination.

$82.7 \times 10^{\circ}$ lymphocytes from each donor; $15 \%$ granulocyte contamination in N.B., $10 \%$ in A.B. 
TABLE II

Comparison of NLT reaction and skin graft rejection in normal volunteers

\begin{tabular}{|c|c|c|c|}
\hline Panels* & Rank order of NLT reactionst & Order of skin graft rejection $\ddagger$ & Onset in days \\
\hline A. & $\begin{array}{l}\text { R.R. }>\text { C.S. }>\text { H.R. }=\text { M.B. } \\
\text { [R.R. > H.R. }=\text { M.B. }(p<0.05) ; \\
\text { C.S. not significantly different from } \\
\text { the others] }\end{array}$ & R.R. $>$ H.R. = M.B. $>$ C.S. & $8-15$ \\
\hline B. & L.B. $=$ P.S. $>$ A.H. $>$ M.S. $(p<.05)$ & M.S. > P.S. > A.H. = L.B. & $6-12$ \\
\hline C. & J.A. $=$ A.H. $=$ D.R. $>$ N.C. $(p<0.05)$ & J.A. $=$ A.H. $=$ D.R. $>$ N.C. & $8-11$ \\
\hline
\end{tabular}

* Each panel consists of one lymphocyte donor and four recipients.

$\dagger$ Reactions produced by lymphocytes of skin graft recipient ranked in order of decreasing induration at 48 hours.

$\mp$ Skin of lymphocyte recipients grafted simultaneously to lymphocyte donor; ranked in order from earliest to latest onset of rejection by gross observation.

The effect of uremia in the cell recipient upon the magnitude of the reaction to injected normal lymphocytes was also investigated. When equal numbers of lymphocytes from the same healthy donor were injected into F.R. and L.R., one of the isogeneic twin pairs used above, there were comparable reactions at 48 hours, although the degree of erythema at 24 hours was depressed in the uremic individual. This observation strengthened the impression that the 24-hour erythema reaction was a manifestation of the host response to the inoculum and not necessarily a part of the putative graft vs. host reaction.

Comparison of the NLT test with skin grafting in panels of normal volunteers. Each of the three panels was considered as a separate experiment in which the time of onset of a skin graft rejection was compared to the size of the NLT reaction seen in the donor of that skin graft. A rank order of rejection of the simultaneously placed grafts was determined by daily inspection. The rapidity of the development of complete necrosis was uniform once the first definite evidence of rejection was noted.

Although at times the panel members displayed small differences among the NLT reactions and skin graft rejection times, it was possible to arrange the results for each panel in rank orders as Brent and Medawar (12) did with their guinea pig experiments. In Table II, the mean 48-hour induration measurements of the skin tests are arranged in decreasing order of magnitude as determined by Duncan's new multiple range test $(p<0.05)$; the skin graft results are similarly arranged with separation requiring at least 1 day's difference in the rejection times. In panel A, the skin tests in R.R. and C.S. were not significantly different in size. In the case of R.R., there was "prediction" of the most rapid skin graft rejection, but C.S., whose reaction did not differ significantly from the other three, had skin. surviving for 7 full days longer than R.R. In panel B, M.S. had the smallest NLT reaction, but skin from this individual was rejected in 6 days, 2 full days ahead of the others. At the same time, L.B., with one of the larger reactions, had a rejection time in 11 to 12 days. In panel $\mathrm{C}$, only one NLT reaction was significantly different from the others, and in this case (N.C.) with the smaller reaction there was survival of the skin graft 2 days beyond the others.

Slightly different rank orders for the NLT reactions were obtained if erythema rather than induration was considered. However, for these studies in which the NLT reaction was being evaluated, we used skin grafting as the standard for establishing which feature of the NLT reaction was most likely to reflect the putative graft vs. host response. Induration at 48 hours gave the best possible correlation, although a disappointing one. Attempts to explain the unexpected results in terms of presensitization by blood transfusions or pregnancy, or by sex or blood group incompatibility, were unsuccessful by simple inspection of the interrelationships of these factors in the panel members. Analyzing the data in Table II in a fashion similar to that used by Gray and Russell (17), i.e., rearranging each panel consisting of four members into six different pairs, we determined the total number of correct and incorrect 
TABLE III

Relationship to outcome of renal allotransplantation (prospective study)*

\begin{tabular}{|c|c|c|c|c|}
\hline $\begin{array}{l}\text { NLT reaction } \\
\text { (induration at } \\
\quad \mathbf{4 8} \text { hours) }\end{array}$ & Patient & Donor relationship & $\begin{array}{l}\text { No. lympho- } \\
\text { cytes in- } \\
\text { jected }\left(\times 10^{6}\right)\end{array}$ & Outcome \\
\hline \multirow[t]{6}{*}{$<3 \mathrm{~mm}$} & M.B. & Mother & & Alive at 27 months; indolent rejection \\
\hline & B.T. & Mcther & 1.8 & Alive at 24 months; no rejection crisis \\
\hline & H.H. & Mother & 2.7 & $\begin{array}{l}\text { Alive at } 19 \text { months; moderate early } \\
\text { rejection crisis, none since }\end{array}$ \\
\hline & P.D. & Mother & 3.6 & $\begin{array}{l}\text { Dead at } 3 \text { months; drug toxicity, re- } \\
\text { jection, gastrointestinal bleeding }\end{array}$ \\
\hline & B.S. & Mother & 5.3 & $\begin{array}{l}\text { Alive at } 26 \text { months; mild early rejection } \\
\text { crisis, recurrent rejection with reduced } \\
\text { renal function since } 16 \text { months }\end{array}$ \\
\hline & K.R. & Mother & 6.0 & $\begin{array}{l}\text { Alive at } 25 \text { months ; mild early rejection, } \\
\text { none since }\end{array}$ \\
\hline \multirow[t]{6}{*}{$3-6 \mathrm{~mm}$} & A.J. & Dizygotic twin & 2.2 & $\begin{array}{l}\text { Dead at } 4 \text { months; moderate rejection, } \\
\text { cryptococcal meningitis }\end{array}$ \\
\hline & W.M. & Dizygotic twin & 3.4 & $\begin{array}{l}\text { Dead at } 12 \text { months; gastrointestinal } \\
\text { bleeding, pulmonary tuberculosis, indo- } \\
\text { lent rejection, and pyelonephritis }\end{array}$ \\
\hline & D.P. & Mother & 3.0 & $\begin{array}{l}\text { Dead at } 11 \text { months; subacute hepatic and } \\
\text { pancreatic necrosis, drug toxicity, and } \\
\text { indolent rejection }\end{array}$ \\
\hline & W.K. & Mother & 5.0 & $\begin{array}{l}\text { Dead at } 14 \text { months; severe early rejection } \\
\text { crisis reversed, died of drug toxicity }\end{array}$ \\
\hline & S.W. & Mother & 4.7 & $\begin{array}{l}\text { Alive at } 26 \text { months; mild early rejection, } \\
\text { possible recurrent glomerulonephritis }\end{array}$ \\
\hline & A.H. & Father & 4.0 & $\begin{array}{l}\text { Dead at } 12 \text { months; indolent rejection, } \\
\text { pyelonephritis, renal failure }\end{array}$ \\
\hline \multirow[t]{4}{*}{$>6 \mathrm{~mm}$} & C.S. & Mother & 2.7 & $\begin{array}{l}\text { Alive at } 25 \text { months; moderate early re- } \\
\text { jection, none since }\end{array}$ \\
\hline & G.J. & Wife & 5.4 & $\begin{array}{l}\text { Dead at } 4 \text { months; severe rejection crisis } \\
\text { reversed, died with drug toxicity, } \\
\text { nocardial lung abscess }\end{array}$ \\
\hline & M.I. & Father & 2.0 & $\begin{array}{l}\text { Alive at } 16 \text { months; moderate early rejec- } \\
\text { tion crisis, none since }\end{array}$ \\
\hline & V.S. & Mother & 2.7 & $\begin{array}{l}\text { Dead at } 8 \text { months ; moderate early rejec- } \\
\text { tion crisis, second moderate rejection at } \\
5 \text { months, died of pancreatic necrosis }\end{array}$ \\
\hline
\end{tabular}

${ }^{*}$ Follow-up 16 to 27 months on surviving patients.

predictions of skin graft survival based on the NLT reaction, using $2 \mathrm{~mm}$ or 1 day as significant differences in the size of the NLT induration or skin graft survival, respectively. Of 18 such pairs arranged from the 12 members of panels $\mathrm{A}, \mathrm{B}$, and $\mathrm{C}$, there were 11 correct and 7 incorrect predictions.

Prospective studies in which the NLT reaction was compared with the results of renal allotransplantation. Sixteen patients receiving renal allotransplants with immunosuppressive therapy are presented in Table III and are arranged according to the size of the NLT reaction produced pre- operatively by their lymphocytes in the kidney donor. Only survivors followed for over 1 year are included in this Table. All patients tested who died are included. The protocols for immunosuppressive therapy including azathioprine, actinomycin $\mathrm{C}$, and steroids did not vary much during the period of these studies, so that the results could not have been much influenced by changing modes of therapy, although V.S. received preoperative thoracic duct drainage. With the exception of one unrelated donor (G.J.), all donors were parents, siblings, or dizygotic twins. It is important to note that the lymphocyte donors were in vari- 
TABLE IV

Reactivity of lymphocytes* after sensitization by renal allotransplantation

\begin{tabular}{lllllll}
\hline \hline & \multicolumn{5}{c}{ Skin test reactions $\dagger$} \\
\cline { 2 - 7 } Patients & L.R. & M.R. & M.Z. & A.M. & G.C. & A.R. \\
\hline H.R. & $4.3 / 0.8 \ddagger$ & $4.0 / 0$ & $7.3 / 0$ & & & \\
D.M. & $5.3 / 4.3$ & & & $12.5 / 8.8 \dagger$ & $12.0 / 5.7$ & \\
R.C. & & $6.7 / 4.8$ & & $13.2 / 6.5$ & $5.7 / 3.2 \dagger$ & \\
J.R. & & & & & & $.20 .0 / 7.0 \dagger$
\end{tabular}

* Injected into donors and other normal individuals. Erythema/induration at 48 hours in millimeters.

t Specific renal transplant donor-recipient combination.

ous stages of chronic uremia when the tests were performed and that some of them had had considerable numbers of hemodialyses with blood transfusions during the weeks before testing. However, the number of transfusions and the degree of uremia per se did not suggest an influence on the NLT reaction produced by lymphocytes from these patients. Although there were differences in the numbers of lymphocytes injected, there was no clear-cut relationship between cell dosage and reaction size.

One important observation to be made from these results is that many uremic lymphocytes were capable of producing moderately large reactions in the skin of close relatives. As for the predictive value of the NLT reaction in choosing kidney donors, the results were only moderately good. Of the six patients in the less than $3 \mathrm{~mm}$ NLT group, only one has not survived, and three of the remaining five recipients are doing very well at more than 1 year post-transplantation. On the other hand, only one patient out of six in the 3- to 6-mm group is still alive. It is of interest, however, that four of the five nonsurvivors in this group had lived for close to 1 year with an indolent type of progressive rejection before succumbing to other complications. Of the four patients in the greater than $6 \mathrm{~mm}$ group, two have done very well, one had a very stormy course with an early severe rejection crisis and subsequent death, and another died at 8 months of pancreatic necrosis with poorly controlled rejection.

On five occasions, lymphocytes from prospective kidney recipients were injected into individuals other than the prospective donor for a total of 11 transfers. Eight of the transfers were to individuals who were neither parent nor sibling to the lymphocyte donor, and in three of the transfers the recipient was the mother of the patient, though not the prospective kidney donor. Of the unrelated lymphocyte recipients, two of eight gave greater, four gave equal, and two gave lesser reactions than the prospective kidney donor. Of the related lymphocyte recipients, one of three gave equal and two gave lesser reactions than the prospective kidney donor.

Reactivity of lymphocytes from individuals with successful renal allografts. Four of our most successful transplant recipients were tested against their donors in a small study designed to assess the combined effects of immunosuppressive therapy and sensitization by tissue grafting upon the ability of lymphocytes to mount an NLT reaction. These tests were performed from 5 months to 5 years after transplantation. None of these patients had had the test performed preoperatively, but the fact that they were clinically well would have led us to expect minimal reactions on the basis of close histocompatibility. In addition, if immunosuppressive drugs had any influence on the NLT reaction, one would have expected a depressive effect. However, the results of the NLT test from these stable drug-treated transplanted recipients to their donors and to other individuals (Table IV) displayed a spectrum of response more like that expected from a panel of normals. Although one individual's lymphocytes (H.R.) were poorly reactive against three people, including his kidney donor, lymphocytes from R.C. and D.M. produced moderate to severe lesions; and indeed, the latter's cells produced the strongest reaction against his paternal donor. J.R., who received a renal allotransplant from his dizygotic twin, was of particular interest because of the large reaction produced by his lymphocytes in the skin of his donor 5 years after transplantation and when no immunosuppressive therapy had been administered for over 2 years. J.R. and A.R. had exchanged skin grafts 5 years previously. All four of these patients had had definite rejection episodes in the past but at the time of the testing were in good general health with normal renal function.

The ability of thoracic duct lymphocytes to produce an NLT reaction. Preliminary studies on the rich supply of lymphocytes available from thoracic duct fistulas, produced as a pretransplant means of depleting the recipient of immunologically 
competent cells, have thus far suggested that these cells are less capable of producing the NLT reaction than the same numbers of lymphocytes obtained from peripheral blood. The latter are invariably contaminated with some granulocytes, platelets, and red cells in contrast to the relatively pure lymphocytic population in thoracic duct lymph. One patient's thoracic duct small lymphocytes produced no reaction in two recipients, whereas three others produced smaller reactions than equal numbers of peripheral blood lymphocytes. The numbers, morphology, and viability (trypan blue) of thoracic duct cells were the same as peripheral blood lymphocytes at the time of testing.

\section{Discussion}

Although the main purpose of this study was to assess the value of the NLT reaction in selecting donors for renal transplantation, certain other features deserve comment since not all investigators agree on the nature and characteristics of the NLT reaction in man. The observations of Brent and Medawar $(12,13)$, which established the immunogenetic basis for the NLT reaction in guinea pigs, serve as a basis for the studies in man. In addition, the earlier studies in chickens by Cock and Simonsen (25) and Terasaki (26) shed important light on the graft vs. host nature of the initial reaction and have identified the circulating lymphocyte as the cell type most likely responsible for the reaction. The term "normal lymphocyte transfer" was chosen to emphasize the unsensitized nature of the cells, in contrast to the "transfer reaction," in which inflammatory nodules in skin are produced by lymphocytes from specifically sensitized animals $(27,28)$. Cells expressed from lymph nodes are ineffective in producing the NLT reaction in guinea pigs $(12)$, whereas this is the usual source of cells for the transfer reaction. Both the degree of sensitization and the source of cells, therefore, are important determinants of the reaction produced by intradermal injections of lymphocytes.

That unsensitized small lymphocytes are capable of reacting against allogeneic tissue is illustrated by Gowans' work (29) in which small lymphocytes from a parental strain produced a fatal wasting disease when injected into $F_{1}$ hybrid rats. Since this reaction morphologically began within
24 hours, it is, therefore, quite possible for a primary immune response to be manifest within 24 to 48 hours. The value of the NLT reaction as a method for estimating histocompatibility in random-bred populations rests on the fact that in the guinea pig the intensity of the reaction is directly related to the vigor of the rejection of skin grafted in the opposite direction, that is, from the lymphocyte recipient to the lymphocyte donor. It is to be assumed, therefore, that the reaction is proportional to the number and strength of histocompatibility antigens present in the dermis of the recipient that are lacking in the transferred lymphocytes of the donor.

Although the graft vs. host nature of the initiating reaction would seem to have been satisfactorily demonstrated in the chicken and guinea pig, certain contradictory evidence in man has been presented by Amos, Nicks, Peacocke, and Sieker (15). Because significant lesions were produced by the injection of purified suspensions of polymorphonuclear leukocytes into the skin of other individuals, a host vs. graft component to the initial lesion has been postulated in man. In Amos' studies, positive reactions were also found occasionally when nonviable (frozen and thawed) allogeneic lymphocytes as well as platelets were injected. Aisenberg's studies (30) on the normal lymphocyte transfer reaction in patients with Hodgkin's disease are of interest because they also suggest that the reaction seen during the first 48 hours is based on something other than the graft vs. host component, which he believes comes later at 7 to 14 days.

There is also some disagreement regarding the incidence of reactions to autologous cell suspensions $(14,17,24)$. The present study demonstrates that transient erythema without induration, unrelated to the degree of granulocyte contamination of the inoculum, was occasionally produced by the injection of autologous and isogeneic cells, but that this reaction was of no consequence at 48 hours. It is possible that the early response to cell injections is due to the release of some unidentified vasoactive principle generated in the process of cell preparation. Materials such as the permeability factor obtained from guinea pig lymphoid tissue (31) might be of importance in a transfer of disrupted human lymphocytes, and one should also give consideration to host factors that 
may play a role in the production of the skin lesion itself. First of all, it is unlikely that the palpable nodule is directly due to the mass of injected proliferating lymphocytes. Although mitotic figures have been reported (17), mitoses were not seen in our biopsies, and in the transfer reaction in rabbits it has been shown that 70 to $80 \%$ of the infiltrating cells are of host and not of donor origin (32). Of great interest also are the findings of Black, Humphrey, and Niven (33) that the abolition of the delayed hypersensitivity skin reaction to tuberculin by posthypnotic suggestion was not due to absence of infiltrating lymphoid cells but to failure of development of the increased vascular permeability and edema normally present. It seems, therefore, that although the normal lymphocyte transfer reaction is initiated by an immune response, the resulting measurable lesion may be greatly determined by nonimmunologic host factors.

Except for two cases in which uremic cells were used, there were no negative allogeneic skin reactions in the present series, in general agreement with most investigators $(15,17)$. However, the $29 \%$ incidence of negative reactions when cells were transferred among healthy volunteers in the studies of Moorhead and Patel (14) is difficult to reconcile with our experience, especially in view of the similar methods of cell preparation and dosage.

The present studies with unrelated normal volunteers and the similar studies reported by Gray and Russell (17) indicate that the predictive ability of the test, insofar as skin grafts are concerned, is poor. We found that the correct order of skin graft rejection could be predicted in only one of the three panels, and in two instances the rejection time was exactly opposite that predicted by the NLT reaction.

Failure to obtain the exact correlation that Brent and Medawar found in the guinea pig could be due to several factors, in addition to differences in the reactivity of individual recipients. There exists the possibility of pre-existing immunity in the cell donors and recipients in the NLT panels. The two major sources of prior exposure to histocompatibility antigens in the present study were blood transfusion and pregnancy. However, there are significant differences in the nature and duration of allograft sensitization induced by intra- dermal leukocytes $(34,35)$ or by skin grafting (36) compared to the sensitization induced by pregnancy or blood transfusion. Although intradermal leukocyte injections produce allograft sensitivity in man, cells given intravenously, as by whole blood transfusion or pregnancy, do not produce appreciable sensitization against tissue allografts, although leukocyte antibodies are produced (37-39). In addition, there is only a suggestive correlation between specific leukoagglutinin types and skin graft rejection times (4). No convincing demonstration of an effect of pregnancy on allograft immunity in man has appeared, although in rodent species sensitization of the fetus by passage of maternal cells into the fetal circulation appears possible (40).

The effects of presensitization on the NLT reaction itself are not fully known, although results in fowl (26) and man (15) indicate that depression of the reaction results when either the donor or the recipient of the lymphocytes is immune.

The effect of $\mathrm{ABO}$ and sex incompatibilities on the NLT reaction have been specifically tested in the studies of Moorhead and Patel (14), who concluded that ABO blood groups and sex did not influence the NLT reaction, at least insofar as incompatibilities did not enhance the reaction. However, their data show a rather striking inhibition of the 24- to 48-hour reaction when $\mathrm{AB}$ incompatibilities were present. Whether blood group isoantibodies are capable of suppressing the reaction by combining with the injected lymphocytes is uncertain. Although 8 of our 12 panel members were $\mathrm{ABO}$ incompatible with their lymphocyte donors and 7 of these would have been expected to have had isoantibody against the cell donors, there is no indication that these individuals had either depression or enhancement of the NLT reaction beyond the expected range in a random population.

It is concluded, then, that if presensitization or $\mathrm{ABO}$ incompatibility were of significance in influencing our NLT panel results, it would be diffcult to designate which, if either, was playing a major role. Indeed, the practical application of the normal lymphocyte transfer test in man would be complicated to an impossible degree if blood groups, sex, parity, and transfusion history had to be considered in every case. On the other hand, since we deliberately chose unrelated individuals 
for the panel members, it may be simply that both skin grafting and the NLT reaction are too insensitive for the assessment of subtle differences between people whom we should expect to be highly incompatible.

Our main concern has been in devising a method of selecting donors for renal allotransplantation. Any test that depends upon the immunologic reactivity of the chronically and often terminally ill patient is subject to variability due to chronic illness and, in particular, to the effect of uremia. It is well known that uremia often results in deficient immunologic reactivity $(41,42)$, and our own observations extend this deficient immunologic state to include the normal lymphocyte transfer reaction. The present studies in identical twins reveal that there is a depression of NLT reactivity during uremia that disappears after correction of the uremic state. Our prospective study in renal allotransplantation may have been complicated by the presence of varying degrees of uremia, but unfortunately it is not possible to assess directly the over-all immunologic competency of each uremic individual. Since, in general, we expected depression of reactivity when uremic cells were placed in the skin of normal individuals, a negative reaction would have lost much of its potential significance. However, we did not obtain completely negative reactions (i.e., less than $2 \mathrm{~mm}$ induration) from uremic cells except in two cases, findings that do not agree with those of Bridges, Nelson, and McGeown (16), who found a significant number of negative reactions when uremic lymphocytes were injected into unrelated individuals.

Although a minimal NLT reaction indicated a favorable result from transplantation, we would not want to use a large reaction as an exclusion test, since uremic lymphocytes from one of our most successful allotransplants (C.S.) produced a vigorous reaction in the skin of his prospective maternal donor. In most cases presented in Table III, the normal lymphocyte transfer reaction was performed only with the prospective donor, so that we are unable to make any comparisons with reactions produced by the same uremic cells in unrelated individuals. However, in the few cases in which this was done, lymphocytes were just as likely to produce smaller reactions in unrelated individuals as larger ones, compared with the reaction in the close relative. It is apparent now that future studies should include wherever possible the injection of cells into at least one other individual in addition to the prospective donor.

Retrospective studies in patients already successfully transplanted provide some interesting information as to their immune competence and perhaps some clues to the mechanism of "tolerance" in human renal transplantation. The rather vigorous reaction produced by the cells of D.M. and J. R. were unexpected, and such reactions are certainly open to more than one interpretation. First of all, it is possible that sensitization by transplantation had increased the reactivity of lymphocytes in a graft vs. host direction because of the weak antigenic differences originally present between donor and recipient (43). If this is so, one must then explain the mechanism that protects the normally functioning kidney without evidence of active rejection. On the other hand, it is possible that the reaction observed was not the result of a graft vs. host but of a host vs. graft reaction that occurred because of sensitization of the lymphocyte recipient (kidney donor) as a result of skin grafted from the kidney recipient (lymphocyte donor) 5 months previously in one instance and $5 \frac{1}{2}$ years in another. This second interpretation, although possible, seems less likely because of the fact that sensitization of the lymphocyte recipient would be more likely to depress rather than enhance the initial reaction. The duration of sensitization as a result of skin grafting should not exceed 2 to 3 months, although conclusive data on this point are lacking. It should be mentioned that the life-span of the circulating small lymphocyte, which is presumably the sensitized cell, may be several years in the human (44). The number of patients studied after transplantation (Table IV) is too small for evaluation of the possible role of other factors such as immunosuppressive drug therapy. However, it is clear that cells from individuals "tolerant" of a successfully functioning allogeneic renal transplant react normally, or perhaps supernormally, against donor tissue. We consider this evidence for sensitization rather than the existence of true tolerance.

Our brief studies on cells obtained from thoracic duct lymph were performed with the second day lymph, consisting almost entirely of the small lym- 
phocytes that should be capable of mounting graft vs. host reactions $(45,46)$. Our preliminary results indicate that this population of cells is less capable of mounting an NLT response than cells obtained from peripheral blood. Whether this depressed reactivity is due to true differences in cell populations or to the presence of inhibiting factors in lymph is a subject for future investigation. It is pertinent to recall that Brent and Medawar (12) found guinea pig lymph node lymphocytes poorly reactive in the NLT reaction compared with peripheral lymphocytes.

On the whole, our studies indicate that the normal lymphocyte transfer reaction in man leaves much to be desired as a histocompatibility test, especially when unrelated volunteers are used in skin graft experiments. Although the NLT results with related donors for renal transplantation are somewhat better, it is possible that the graft vs. host component that we seek is in many cases overshadowed by host reactions that apparently are not operable in the guinea pig. We are not using the NLT reaction as a selection test for transplant donors, therefore. We must also consider the very real possibility of transmitting viral diseases by intradermal injections. Although we have not been aware of any such instance in our series, the risk must be weighed against the benefits to be gained from performing the test. Hypersensitivity reactions to dextran have also been reported (47), and the test does induce a state of immunity in the recipient, the long-term effects of which cannot be ascertained at this time.

\section{Summary}

Intradermally injected allogeneic blood lymphocytes produce delayed type skin reactions in man. We have investigated several features of this normal lymphocyte transfer reaction (NLT) to assess its applicability to histocompatibility testing.

Although nonviable and autologous cells occasionally produced some reaction, mostly erythema, at 24 hours, such controls were always negative at 48 hours. On the other hand, only 2 of 59 allogeneic transfers were negative, and these were with cells from uremic patients. Comparison of isogeneic cells from twins, one uremic and the other healthy, provided direct evidence that the NLT reaction is poorly produced by cells from uremic individuals. Measurement of induration at 48 hours proved to be the most stable measure of the putative graft vs. host reaction. A second recrudescent reaction occurred in many patients after 6 to 8 days and strongly suggests that a host vs. graft response follows the initial graft vs. host reaction at 24 to 48 hours.

When normal unrelated volunteers were randomly grouped into panels in which the results of skin grafting were compared to the NLT reactions, the predictive ability of the test was poor. The NLT reaction was as likely to give an incorrect prediction as a correct one when considering the rank order of skin test sizes in relation to the rank order of skin graft rejections.

The predictive value of the NLT reaction for renal allografting was studied prospectively in 16 patients followed to survival times of 16 to 27 months, or to death. Among those who had an NLT reaction with their prospective donors of less than $3 \mathrm{~mm}$ in diameter, five of six are alive. Of the patients in the 3- to 6-mm category, only one of six is alive, whereas two of four in the greater than $6 \mathrm{~mm}$ category are alive. The test is of value, therefore, in indicating those patients most likely to do well, namely those with minimal NLT reactions. However, large reactions are not necessarily indicative of marked incompatibility.

Retrospective studies in which four successfully transplanted patients were tested against their kidney donors and others showed that lymphocytes from stable drug-treated patients produced normal, and sometimes rather vigorous, reactions. For reasons as yet unknown thoracic duct small lymphocytes produce much smaller NLT reactions than peripheral blood lymphocytes.

\section{Acknowledgments}

We express our appreciation to Drs. Karl Herwig, Mario Labardine, and Jacques Poisson for their assistance in performing the skin grafts.

\section{References}

1. Murray, J. E., R. Gleason, and A. Bartholomay. Fourth report of the human kidney transplant registry: 16 September 1964 to 15 March 1965. Transplantation 1965, 3, 684 . 
2. Van Rood, J. J., and A. Van Leeuwen. Defined leucocyte antigenic groups in man in Histocompatibility Testing. Washington, National Academy of Sciences, 1965, publication 1229, p. 21.

3. Van Rood, J. J., and A. Van Leeuwen. Leucocyte grouping. A method and its application. J. clin. Invest. 1963, 42, 1382.

4. Van Rood, J. J., A. van Leeuwen, J. G. Eernisse, E. Frederiks, and L. J. Bosch. Relationship of leukocyte groups to tissue transplantation compatibility. Ann. N. Y. Acad. Sci. 1964, 120, 285.

5. Terasaki, P. I., T. L. Marchioro, and T. E. Starzl. Sero-typing of human lymphocyte antigens: preliminary trials on long-term kidney homograft survivors in Histocompatibility Testing. Washington, National Academy of Sciences, 1965, publication 1229 , p. 83.

6. Walford, R. L., R. Gallagher, and G. M. Troup. Human lymphocyte typing with isologous antisera; technical considerations and a preliminary study of the cytotoxic reaction system. Transplantation $1965,3,387$.

7. Bach, F., and K. Hirschhorn. Lymphocyte interaction: a potential histocompatibility test in vitro. Science 1964, 143, 813.

8. Bain, B., M. R. Vas, and L. Lowenstein. The development of large immature mononuclear cells in mixed leucocyte cultures. Blood 1964, 23, 108.

9. Rubin, A. L., K. H. Stenzel, K. Hirschhorn, and F. Bach. Histocompatibility and immunological competence in renal homotransplantation. Science 1964, 143, 815.

10. Wilson, R. E., L. Henry, and J. P. Merrill. A model system for determining histocompatibility in man. J. clin. Invest. 1963, 42, 1497.

11. Ramseier, H., and J. W. Streilein. Homograft sensitivity reactions in irradiated hamsters. Lancet 1965, 1, 622.

12. Brent, L., and P. B. Medawar. Tissue transplantation: a new approach to the "typing" problem. Brit. med. J. 1963, 2, 269.

13. Brent, L., and P. B. Medawar. Nature of the normal lymphocyte transfer reaction. Nature (Lond.) 1964, 204, 90.

14. Moorhead, J. F., and A. R. Patel. Influence of sex and $\mathrm{ABO}$ blood group on the normal lymphocyte transfer test. Brit. med. J. 1964, 2, 1111.

15. Amos, D. B., P. J. Nicks, N. Peacocke, and H. O. Sieker. An evaluation of the normal lymphocyte transfer test in man. J. clin. Invest. 1965, 44, 219.

16. Bridges, J. M., S. D. Nelson, and M. G. McGeown. Evaluation of lymphocyte transfer test in normal and uraemic subjects. Lancet 1964, 1, 581.

17. Gray, J. G., and P. S. Russell. The lymphocyte transfer test in man in Histocompatibility Testing. Washington, National Academy of Sciences, 1965, publication 1229 , p. 105 .

18. Carpenter, C. B., R. J. Glassock, and J. P. Merrill. Normal lymphocyte transfer (NLT) test in humans in Histocompatibility Testing. Washington,
National Academy of Sciences, 1965, publication 1229, p. 173.

19. Pappenheimer, A. M. Experimental studies upon lymphocytes. I. The reactions of lymphocytes under various experimental conditions. J. exp. Med. 1917, 28, 633.

20. Marshall, D. C., E. A. Friedman, D. P. Goldstein, L. Henry, and J. P. Merrill. The rejection of skin homografts in the normal human subject. Part I. Clinical observations. J. clin. Invest. 1962, 41, 411.

21. Henry, L., D. C. Marshall, E. A. Friedman, G. J. Dammin, and J. P. Merrill. The rejection of skin homografts in the normal human subject. Part II. Histological findings. J. clin. Invest. 1962, 41, 420.

22. Steel, R. G. D., and J. H. Torrie. Principles and Procedures of Statistics. New York, McGrawHill, 1960.

23. Goldsmith, K. L. G. Choosing donors for tissue transplantation. Lancet 1964, 1, 614.

24. Wolf-Jürgensen, $P$., and $M$. Schwartz. Normallymphocyte transfer in man. Basophil leucocytes in delayed skin reaction. Lancet 1964, 2, 388.

25. Cock, A. G., and M. Simonsen. Immunological attack on newborn chickens by injected adult cells. Immunology 1958, 1, 103.

26. Terasaki, P. I. Identification of the type of bloodcell responsible for the graft-versus-host reaction in chicks. J. Embryol. exp. Morph. 1959, 7, 394.

27. Brent, L., J. Brown, and P. B. Medawar. Skin transplantation immunity in relation to hypersensitivity. Lancet 1958, 2, 561.

28. Brent, L., J. B. Brown, and P. B. Medawar. Quantitative studies on tissue transplantation immunity. VI. Hypersensitivity reactions associated with the rejection of homografts. Proc. roy. Soc. B 1962, 156, 187.

29. Gowans, J. L. The fate of parental strain small lymphocytes in $F_{1}$ hybrid rats. Ann. N. Y. Acad. Sci. 1962, 99, 432.

30. Aisenberg, A. C. Studies of lymphocyte transfer reactions in Hodgkin's disease. J. clin. Invest. 1965, 44, 555.

31. Willoughby, D. A., B. Boughton, and H. O. Schild. A factor capable of increasing vascular permeability present in lymph node cells. A possible mediator of the delayed reaction. Immunology 1963, 6, 484.

32. Kosunen, T. U., and H. F. Dvorak. The "transfer reaction" in the rabbit. II. A radioautographic Study. Lab. Invest. 1963, 12, 628.

33. Black, S., J. H. Humphrey, and J. S. F. Niven. Inhibition of Mantoux reaction by direct suggestion under hypnosis. Brit. med. J. 1963, 1, 1649.

34. Friedman, E. A., J. W. Retan, D. C. Marshall, L. Henry, and J. P. Merrill. Accelerated skin graft rejection in humans preimmunized with homologous peripheral leukocytes. J. clin. Invest. 1961, 40, 2162. 
35. Rapaport, F. T., J. Dausset, J. M. Converse, and H. S. Lawrence. Biological and ultrastructural studies of leucocyte fractions as transplantation antigens in man. Transplantation 1965, 3, 490.

36. Merrill, J. P., E. A. Friedman, R. E. Wilson, and D. C. Marshall. The production of "delayed type" cutaneous hypersensitivity to human donor leukocytes as a result of the rejection of skin homografts. J. clin. Invest. 1961, 40, 631.

37. Ceppellini, R., P. L. Mattiuz, and M. Curtoni. Characteristics and evolution of leukoagglutinins developed in a patient receiving multiple transfusions from selected donors in Histocompatibility Testing. Washington, National Academy of Sciences, 1965, publication 1229 , p. 71.

38. Ceppellini, R., F. Celada, P. L. Mattiuz, and A. Zanalda. Study of the possible correlation between blood antigens and histocompatibility in man. I. Production of leukoagglutinins by repeated transfusions from one donor. Ann. N. Y. Acad. Sci. 1964, 120, 335.

39. Colombani, J., M. Colombani, and J. Dausset. Leukocyte antigens and skin homograft in man. Demonstration of humoral antibodies after homografting by the antiglobulin consumption test. Ann. N. Y. Acad. Sci. 1964, 120, 307.
40. Billingham, R. E., J. Palm, and W. K. Silvers. Transplantation immunity of gestational origin in infant rats. Science 1965, 147, 514.

41. Dammin, G. J., N. P. Couch, and J. E. Murray. Prolonged survival of skin homografts in uremic patients. Ann. N. Y. Acad. Sci. 1957, 64, 967.

42. Kirkpatrick, C., W. E. C. Wilson, and D. W. Talmage. Immunologic studies in human organ transplantation. I. Observation and characterization of suppressed cutaneous reactivity in uremia. J. exp. Med. 1964, 119, 727.

43. Simonsen, M. Graft versus host reactions. Their natural history, and applicability as tools of research. Progr. Allergy 1962, 6, 349.

44. Brown, W. M. C., K. E. Buckton, and A. S. McLean. Quantitative studies of chromosome aberrations in man following acute and chronic exposure to $\mathrm{x}$ rays and gamma rays. Lancet 1965, 1, 1239.

45. Gowans, J. L., D. D. McGregor, and D. M. Cowen. Initiation of immune responses by small lymphocytes. Nature (Lond.) 1962, 196, 651.

46. Billingham, R. E., W. K. Silvers, and D. B. Wilson. Further studies on adoptive transfer of sensitivity to skin homografts. J. exp. Med. 1963, 118, 397.

47. Kabat, E. A., and D. Berg. Dextran-an antigen in man. J. Immunol. 1953, 70, 514. 